\title{
Establishment of cytochrome P450 3A4 and glutathione S-transferase A1-transfected human hepatoma cell line and functional analysis
}

\author{
B.X. Chang ${ }^{1}$, S.L. You ${ }^{2}$, H.L. Liu ${ }^{2}$, P.Y. Mao ${ }^{3}$ and S.J. Xin ${ }^{2}$ \\ ${ }^{1}$ Non-Infectious Liver Diseases Diagnosis and Treatment Center, \\ 302 Military Hospital, Beijing, China \\ ${ }^{2}$ Liver Failure Treatment and Research Center, 302 Military Hospital, \\ Beijing, China \\ ${ }^{3}$ Experimental Technologies and Research Center, 302 Military Hospital, \\ Beijing, China \\ Corresponding authors: S.J. Xin / P.Y. Mao \\ E-mail: xinshaojiecn@163.com / maopy302@163.com
}

Genet. Mol. Res. 13 (3): 6949-6961 (2014)

Received March 28, 2013

Accepted November 29, 2013

Published April 14, 2014

DOI http://dx.doi.org/10.4238/2014.April.14.11

\begin{abstract}
This study aimed to enhance the drug metabolism function of the human hepatoma cell line $\mathrm{C} 3 \mathrm{~A}$ and to explore the related significance for patients with severe liver disease. The important liver phase I and phase II drug metabolism enzymes, cytochrome P450 3A4 (CYP 3A4) and glutathione S-transferase A1 (GST A1), were constructed into a double expression vector and then transfected into C3A cells. Furthermore, in order to increase the expression of CYP 3A4 and GST A1, they were optimized according to human optimal codons. Another double-expression vector, pBudCE4.1-optimized CYP 3A4-optimized GST A1, was constructed and then transfected into C3A to establish a stable cell line. The drug metabolism function of $\mathrm{C} 3 \mathrm{~A}$ was evaluated. Sequence determination and analysis results showed that the recombinant plasmid pBudCE4.1-CYP 3A4-GST A1 met the application standard and its transfection was successful. The expression and activity of CYP 3A4 and GST A1 in unoptimized C3A cells
\end{abstract}


were higher than those in blank C3A cells. Unoptimized C3A had a better drug metabolism function. Although some C3A cells transfected with pBudCE4.1-optimized CYP 3A4-optimized GST A1 survived, they grew slowly, and were therefore not applicable in clinical practice. Unoptimized $\mathrm{C} 3 \mathrm{~A}$ is superior to blank $\mathrm{C} 3 \mathrm{~A}$ in drug metabolism, and could be applied in the bioartificial liver support system as a new material.

Key words: Cytochrome P450 3A4; Glutathione S-transferase A1; Bioartificial liver support system

\section{INTRODUCTION}

Drug metabolic activity is the most important detoxification function of the liver. Under normal circumstances, drug metabolism is realized by the drug metabolism enzymatic system through phase I and/or phase II reactions, in which toxic substances are transformed into highly water-soluble metabolites and then excreted from the body through urine or bile (Bertz and Granneman, 1997). Thus, drug metabolism is closely correlated with phase I and phase II reactions.

Patients with liver disease suffer from drug metabolism function damage; drug metabolism mediated by cytochrome P450 (CYP450) is damaged more severely than that mediated by phase II drug metabolism enzymes, and both the extent and activity injuries of CYP450 expression are correlated with disease severity. In addition, CYP1A, CYP2C19, and CYP3A are more sensitive to liver disease compared with other enzymes (Farrell, 1999). CYP450 is a phase I metabolic enzyme, and can metabolize different chemicals and drugs and catalyze the metabolisms of numerous endogenous and exogenous compounds, including xenobiotics, drugs, environmental poisons, steroids, fatty acids, and so on. Furthermore, CYP450 can reduce drug toxicity, in which the toxicity of drugs at a normal dose can be removed from the body at a reasonable rate in most cases (Nelson et al., 1996). Glutathione S-transferase (GST) is a phase II metabolic enzyme, and can catalyze the binding of glutathionestimulating hormone (GSH) to electron affinity substances for the sake of excretion.

Both CYP450 and GST are supergene families comprising numerous isozymes. CYP $3 \mathrm{~A} 4$, which is primarily expressed in the liver, is the most important as well as the most abundant CYP450 isozyme in the liver, accounting for $60 \%$ of total liver CYP450. CYP $3 \mathrm{~A} 4$ can metabolize more than 120 kinds of drugs and participates in $60 \%$ of clinical drug metabolisms to different degrees; 40 to $50 \%$ of phase I drug metabolisms are performed by CYP 3A4 (McKinnon et al., 1995; Nelson et al., 1996). Patients with liver disease show different degrees of reduced CYP 3A4 expression and weakened CYP 3A4 activity (Huet and Villeneuve, 1983; Kleinbloesem et al., 1986; Lown et al., 1992; Chalasani et al., 2001; Yang et al., 2003; Horiike et al., 2005). GST constitutes one part of the cell's own defenses to block multiple endogenous and environmental toxic compounds, and protects macromolecules from active electron affinity substance attacks (Strange et al., 2001). The primary substrates of GST include polycyclic aromatic hydrocarbons derived from CYP450 catalysis, the by-products of oxidizing reactions, industrial pollutants and chemicals, chemotherapeutics, halogen solvents, and so on (Hayes and Pulford, 1995). In the liver, the alpha type of GST (GSTA) is superior to other types in both activity and content, among which GST A1 and GST A2 account for 3\% of total cytoplasmic proteins. GST A1-1 has the function of imposing GSH on electron affinity substances with varying structures and then promoting 
their degradation and removal in the cell and/or their excretion out of the cell. GSTs can also serve as transporters of lipophilic compounds, such as bilirubin, cholic acids, steroid hormones, and different exogenous compounds, and participates in steroid hormone syntheses (Johansson and Mannervik, 2001). Some GSTA isoenzymes possess selenium-independent glutathione peroxidase (GPx) activity, which can clear lipidic free radicals, playing an anti-lipid peroxidative role. Furthermore, GPx activity is primarily presented by GSTA. Being an important member of the GSTA family, GST A1-1 also has high GPx activity. When severe liver disease occurs, the expression and activity of enzymes in the liver will be affected, which will in turn affect the drug metabolism function of the liver and the curative effect of drugs, leading to further liver impairment.

The use of a bioartificial liver system is a newly emerging technique in the treatment of severe liver disease, which has attracted increasing research attention. This technique involves the use of hepatic cells in a bioreactor to partially perform the functions of hepatic cells in the liver such as synthesis, metabolism, and detoxification. Therefore, hepatic cells cultured in the bioreactor occupy the central position in the system whose functions directly determine the system's curative effect.

The current study aimed to find an effective cell material for the bioartificial liver support system. To accomplish this goal, CYP 3A4 and GST A1 were constructed into doubleexpression plasmids, which were then transfected into C3A cells for stable C3A cell line establishment. Then, the drug metabolism function of $\mathrm{C} 3 \mathrm{~A}$ cells was evaluated.

\section{MATERIAL AND METHODS}

\section{Gene amplification}

GST A1 and CYP 3A4 primers were designed for their respective amplifications in the open reading frames (ORF) of clones. The amplified fragments were named GST A1 and CYP 3A4. The amplification system volume was $50 \mu \mathrm{L}$. The primer sequences of GST A1 were [5'-ACGCGTCGACGCCGCCACCATGGCAGAGAAGCCCAAGCT-3' (forward) and 5'-C GCGGATCCTTAAAACCTGAAAATCTTCCTTGCT-3' (reverse); the underlined parts indicate the BamHI and SalI sites, respectively]. Those of CYP 3A4 were CYP 3A4 [5'-AGAAT GCGGCCGCGCCACCATGGCTCTCATCCCAGACTTGG-3' (forward) and CYP 3A4-2R, 5'-CCGCTCGAGTCAGGCTCCACTTACGGTGC-3' (reverse); the underlined parts indicate the $N o t \mathrm{I}$ and $X h o I$ sites, respectively]. In the amplification conditions, an initial pre-denaturation step was performed at $94^{\circ} \mathrm{C}$ for $3 \mathrm{~min}$. This was followed by 25 cycles of $94^{\circ} \mathrm{C}$ for $30 \mathrm{~s}, 60^{\circ} \mathrm{C}$ for $30 \mathrm{~s}$, and $68^{\circ} \mathrm{C}$ for $1.5 \mathrm{~min}$. The final exposure was implemented at $68^{\circ} \mathrm{C}$ for $5 \mathrm{~min}$.

\section{pBudCE4.1-CYP 3A4-GST A1 construction}

The polymerase chain reaction (PCR) products GST A1 and the vector pBudCE4.1 were respectively digested by Bam HI/SalI. The digested products were ligated and then transformed into competent DH5 $\alpha$ cells. The yielded plasmid was named pBudCE4.1-GST A1. Monoclonal cells were selected and cultured with Zeocin antibiotic-containing medium $(5 \mathrm{~mL} 50 \mu \mathrm{g} / \mathrm{mL}$ Luria-Bertani liquid) at $200 \mathrm{rpm}$ and incubated at $37^{\circ} \mathrm{C}$ overnight for plasmid extraction.

The PCR products CYP 3A4 and pBudCE4.1-GST A1 were respectively digested by Not $\mathrm{I} / X h o$ I. The digested products were ligated and then transformed into competent DH5 $\alpha$ 
cells. The yielded plasmid was named pBudCE4.1-CYP 3A4-GST A1. Monoclonal cells were selected and cultured in the same way as described above for GST A1. Gene fragments in the recombinant clones were confirmed by sequencing.

\section{Zeocin-sensitivity assays (kill curves)}

C3A cells in logarithmic phase were inoculated onto a 24-well plate at a 1:10 density ratio. After $24 \mathrm{~h}$ growth, 150-600 $\mu \mathrm{g} / \mathrm{mL}$ Zeocin antibiotic was added (the dosage gradients were determined according to the screening information of the target cells within the antibiotic dosage range). Two pores were set for each gradient. Cell growth was observed and recorded successively. The Zeocin-containing medium was replaced every 3 days. Then, the optimal antibiotic dosage was determined as that which could lead to numerous cell deaths within 3 days and killed all cells within 2 weeks.

\section{Transient cotransfection}

Recombinant pBudCE4.1-CYP 3A4-GST A1 plasmids were prepared using a highquality plasmid extraction kit. C3A cells were inoculated onto a 6-well plate at a density of 5 x $10^{5}$ cells/well and cultured overnight. Cell growth was observed. When the cells grew to a coverage rate of approximately $80 \%$, transfection was performed using a Lipofectamine 2000 kit. The transfected cells were named unoptimized C3A. The obtained cells were cultured in a $5 \% \mathrm{CO}_{2}$ incubator at $37^{\circ} \mathrm{C}$ for $4-6 \mathrm{~h}$. Then, the medium was replaced with antibiotic-free minimal essential medium (MEM) for further culture in $5 \% \mathrm{CO}_{2}$ air at $37^{\circ} \mathrm{C}$ overnight. Stably transfected cell lines were screened at $24 \mathrm{~h}$ and target gene expression was determined at $48 \mathrm{~h}$.

\section{Stably transfected cell line screening}

The unoptimized cells were digested at $24 \mathrm{~h}$ after transfection and then inoculated onto five $10-\mathrm{cm}$ cell culture dishes (one for the blank control group) according to a 1:30 ratio. After adherence, $400 \mu \mathrm{g} / \mathrm{mL}$ Zeocin antibiotic-containing MEM (the optimal screening concentration) was added. Screening was observed. The medium was replaced every 3 days. When all cells in the blank control group died, the cells in the unoptimized C3A group had already completed their cloning. All of the cells were digested and then put together onto a 6-well plate for further culture. They were amplified and then frozen.

\section{Quantitative PCR (qPCR) for gene expression analysis}

Total RNA was extracted from the unoptimized C3A using the Trizol method and then reverse transcribed into cDNA using a reverse transcription kit. The obtained cDNA was stored at $-20^{\circ} \mathrm{C}$.

The expression of the target genes and GAPDH (the internal standard gene) was determined using qPCR. Cycle threshold $(\mathrm{Ct})$ values were obtained according to the qPCR curves. Then, the relative expression levels of the target genes were calculated using the $\Delta^{\prime} \Delta^{\prime} \mathrm{Ct}$ method. The blank C3A was used as the control. The formula was as follows: $\Delta \Delta^{\prime} \mathrm{Ct}=$ (the mean $\mathrm{Ct}$ value of target gene in the determined sample - mean $\mathrm{Ct}$ value of GAPDH in the de- 
termined sample) - (the mean $\mathrm{Ct}$ value of the target gene in the control sample - mean $\mathrm{Ct}$ value of GAPDH in the control sample). The gene expression level was determined as $F=2^{-\Delta \Delta C t}$.

The primer sequences (5'-3') used for target gene detection were follows: 1) GST A1 in the unoptimized C3A: CTGAGCCGGGCTGACATTC (forward) and GGGCTGCCAGGCT GTAGAA (reverse); 2) CYP 3A4 in the unoptimized C3A: CACCCACCTATGATACTGTGC TAC (forward) and TCTATGTTGTCCTTGTTCTTCTTGC (reverse); and 3) GAPDH-F: GAAGGTCGGAGTCAACGGATT (114 bp) and GADPH-R: CGCTCCTGGAAGATGGTG AT (341C bp). The amplification conditions consisted of $95^{\circ} \mathrm{C}$ for $2 \mathrm{~min}, 40$ cycles of $95^{\circ} \mathrm{C}$ for $10 \mathrm{~s}, 60^{\circ} \mathrm{C}$ for $30 \mathrm{~s}$, and $70^{\circ} \mathrm{C}$ for $45 \mathrm{~s}$, and $70^{\circ}-95^{\circ} \mathrm{C}$.

\section{3-(4, 5-Dimethylthiazol-2-yl)-2, 5-diphenyltetrazolium bromide (MTT) assays}

To clarify whether the increase in CYP 3A4 and GST A1 expression would inhibit cell growth, MTT assays were performed for cell proliferation detection.

Cells at a density of 6000 cells $/ 100 \mu \mathrm{L}$ density were inoculated onto a 96-well plate. Three wells were set for the blank and unoptimized groups at each detection time. Each well was filled with $100 \mu \mathrm{L}$ phosphate-buffered saline. MTT assays were performed at 24, 48, 72, and $96 \mathrm{~h}$, respectively. Absorbance at a 570-nm wavelength was determined, and cell proliferation curves were drawn.

\section{Biochemical index detection}

Biochemical indexes in cell culture supernatant fluids were detected. A total of $5 \times 10^{5}$ cells of the different groups were placed in 5 - $\mathrm{mL}$ culture flasks and cultured with $5 \mathrm{~mL}$ MEM containing $10 \%$ fetal bovine serum (FBS). The medium was changed every day. When the cells grew to a monolayer (at about $72 \mathrm{~h}$ ), prealbumin, cholinesterase, glucose, and creatinine in the culture supernatant fluid were detected using an OLYMPUS AU5400 automatic biochemistry analyzer (OLYMPUS, Japan). Alpha-fetoprotein (AFP) was detected using immunoturbidimetry. Human albumin was detected using an enzyme-linked immunosorbent assay (Shanghai RB, China).

\section{CYP 3A4 activity detection}

CYP 3A4 activity was detected using liquid chromatography-tandem mass spectrometry (LC-MS). The liquid phase conditions consisted of $5 \mu \mathrm{m}, 2.0 \times 100 \mathrm{~mm}$ Capcell PAK C18 90303 columns (Shiseido, Japan) and a mobile phase of water, containing $0.1 \%$ formic acid and $5 \mathrm{mM}$ ammonium formate, and acetonitrile, containing $0.1 \%$ formic acid, at a $70: 30$ ratio and a $0.2-\mathrm{mL} / \mathrm{min}$ flow rate. The MS conditions consisted of electrospray positive ionization at a $350^{\circ} \mathrm{C}$ capillary temperature, 150 impact energy, $+4000 \mathrm{~V}$ capillary voltage, and 326 selected ion mass spectral $(\mathrm{m} / \mathrm{z})[(\mathrm{M}+1$; midazolam (MDZ), $342(\mathrm{M}+1$; hydroxyl-MDZ), and $260(\mathrm{M}+1$; the internal standard propranolol (PRO)].

Approximately $5 \times 10^{5}$ cells were inoculated onto a 6-well plate (three wells for each group). They were cultured with $2 \mathrm{~mL}$ MEM containing $10 \% \mathrm{FBS}$ in a $5 \% \mathrm{CO}_{2}$ and saturated humidity incubator at $37^{\circ} \mathrm{C}$ overnight. Then, the plate was taken out and the cells were washed twice with serum-free MEM. A final concentration of $1 \mu \mathrm{g} / \mathrm{mL}$ MDZ (the initial concentration was $1 \mathrm{mg} / \mathrm{mL}$ ) was prepared with serum-free culture medium and incubated for a few minutes 
at room temperature. Two-milliliter MDZ-containing MEM was added to each well. The cells were cultured in a $5 \% \mathrm{CO}_{2}$ and saturated humidity incubator at $37^{\circ} \mathrm{C}$ for $1 \mathrm{~h}$. One hundredmicroliter culture medium from each well was transferred to a microtube, and $300 \mu \mathrm{L} 100 \mathrm{ng} /$ $\mathrm{mL}$ PRO-containing stop buffer was added to terminate the reactions.

The $1 \mathrm{mg} / \mathrm{mL}$ MDZ mother liquid was diluted into 10, 20, 50, 200, 500, and $1000 \mathrm{ng} /$ $\mathrm{mL}$ standard curve fluids with the cell culture liquid, and then mixed with the $100 \mathrm{ng} / \mathrm{mL}$ PROcontaining stop buffer in a three-fold volume. The mixture was swirled for 2 min and then centrifuged for $10 \mathrm{~min}$. Ten-microliter supernatant was applied for LC-MS detection.

\section{Immunohistochemistry}

The expression of GSTA1 in the unoptimized C3A cells and in the blank C3A cells was examined by immunohistochemistry.

\section{Examination of metabolic function (lidocaine transformation test)}

To examine the metabolic function of the unoptimized C3A cells and the blank C3A cells, a $20-\mathrm{mg} / \mathrm{mL}$ lidocaine hydrochloride solution was diluted to $80 \mathrm{mg} / \mathrm{L}$ with MEM containing $10 \% \mathrm{FBS}$ and with MEM containing $400 \mu \mathrm{g} / \mathrm{mL}$ Zeocin and $10 \% \mathrm{FBS}$, respectively. The media on the 24-well plate were removed and $1 \mathrm{~mL}$ lidocaine solution was added into each well. Five-hundred microliter culture solution sample was kept at 2, 8, 12, and $24 \mathrm{~h}$. The samples were sent to the Material Identification Center of the Ministry of Public Security for lidocaine concentration determination using a microfluidic toxicant fast-testing instrument.

\section{RESULTS}

\section{Vector construction}

The PCR products amplified in the GST A1- and CYP 3A4-containing ORFs were analyzed on the electrophoresis gel. The results showed that the four fragments conformed to the designed length standards of GST A1 (669 bp) and CYP 3A4 (1512 bp) (Figure 1A).

The vector pBudCE4.1 was analyzed on the electrophoresis gel after BamHI/SalI digestion. The result showed that the obtained fragments conformed to the length standard of pBuDCE 4.1 (about 4595 bp; Figure 1B).

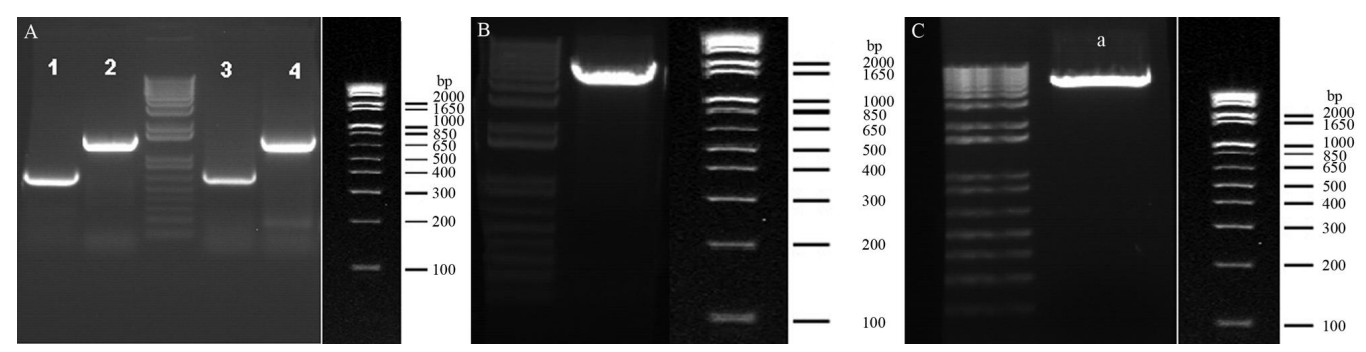

Figure 1. A. Agarose gel electropherogram of PCR products. Fragments 1 and $3=$ GST A1; Fragments 2 and $4=$ CYP 3A4. B. Electropherogram of the vector pBudCE4.1 after BamHI/SalI digestions. C. Electropherogram of the plasmid pBudCE4.1-GST A1 after NotI/XhoI digestions. 
The pBudCE4.1-GST A1 construct was analyzed on the electrophoresis gel after NotI/ XhoI digestion. The result showed that the yielded fragments conformed to the length standard (5264 bp; Figure 1C). The insertion sequences downstream of the pCMV promoter in pBudCE4.1-CYP 3A4-GST A1 were compared with the GST A1 sequences in GenBank. The result showed that the obtained sequences were consistent with published sequences designated as NM_145740.3 and GI: 21527698 . The insertion sequences downstream of the pEF$1 \alpha$ promoter in $\mathrm{pBudCE} 4.1-\mathrm{CYP} 3 \mathrm{~A} 4-\mathrm{GST}$ A1 were compared with the CYP $3 \mathrm{~A} 4$ sequences in GenBank. The result showed that the obtained sequences were consistent with published sequences designated as NM_017460.3 and GI: 13904851.

\section{Zeocin-sensitivity assays}

The sensitivity of C3A to $150-600 \mu \mathrm{g} / \mathrm{mL}$ Zeocin was tested. The results showed that the optimal Zeocin concentration was $400 \mu \mathrm{g} / \mathrm{mL}$; at this concentration, Zeocin killed nearly all of the cells within 2 weeks, leaving the few surviving cells with great morphological changes. These results were consistent with the descriptions indicated in the Zeocin instructions.

\section{qPCR}

CYP 3A4 expression was determined using qPCR. The results showed that the expression levels in the transient and stable transfection unoptimized C3A groups were 45,467,531.15 and 256,452.7175 times higher than in the blank C3A group, respectively (Figure 2A).

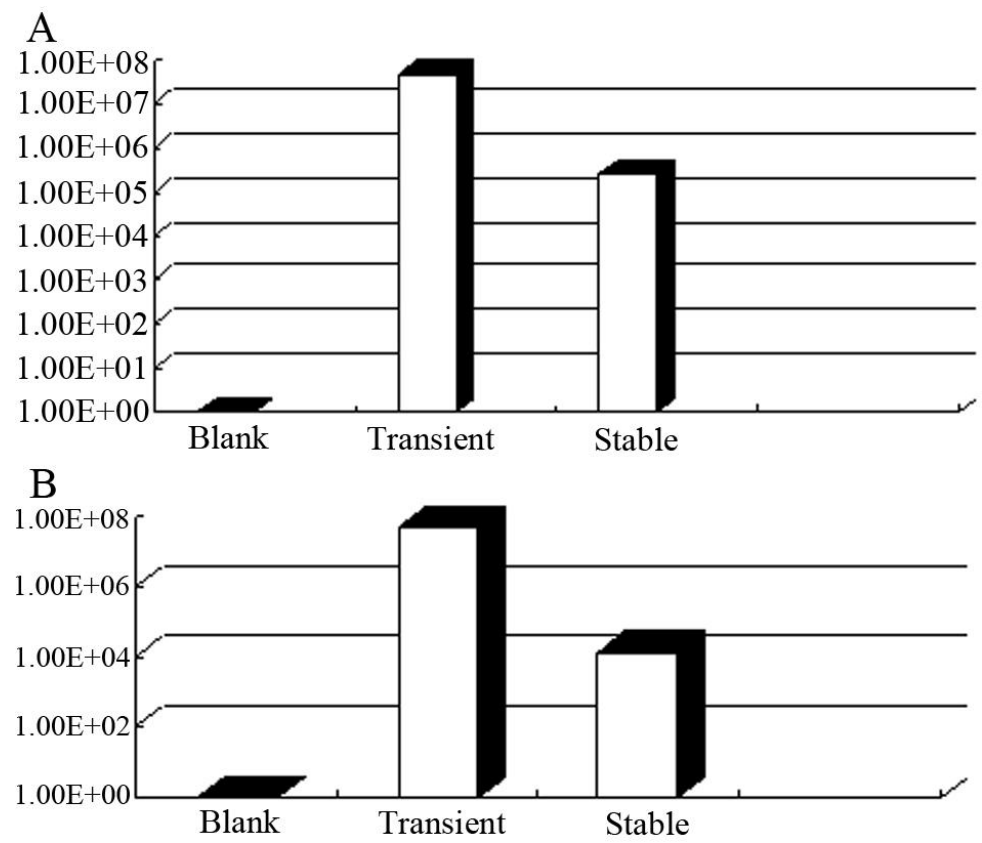

Figure 2. A. Quantitative results of CYP $3 \mathrm{~A} 4$ expression in the blank C3A group and in the transient and stable transfection unoptimized C3A groups. B. Quantitative results of the GST A1 expression in the blank C3A group and in the transient and stable transfection unoptimized C3A groups. 
GST A1 expression was also determined. The results showed that the expression levels in the transient and stable transfection unoptimized C3A groups were 47,893,725.72 and 13,493.71523 times higher than in the blank C3A group, respectively (Figure 2B).

\section{MTT assays}

The MTT assays showed that the growth rate of the unoptimized C3A group was lower than that of the blank C3A group (Figure 3A). This finding indicates that an increase in CYP 3A4 and/or GST A1 expression inhibits cell growth.

\section{A Cell proliferation assay}
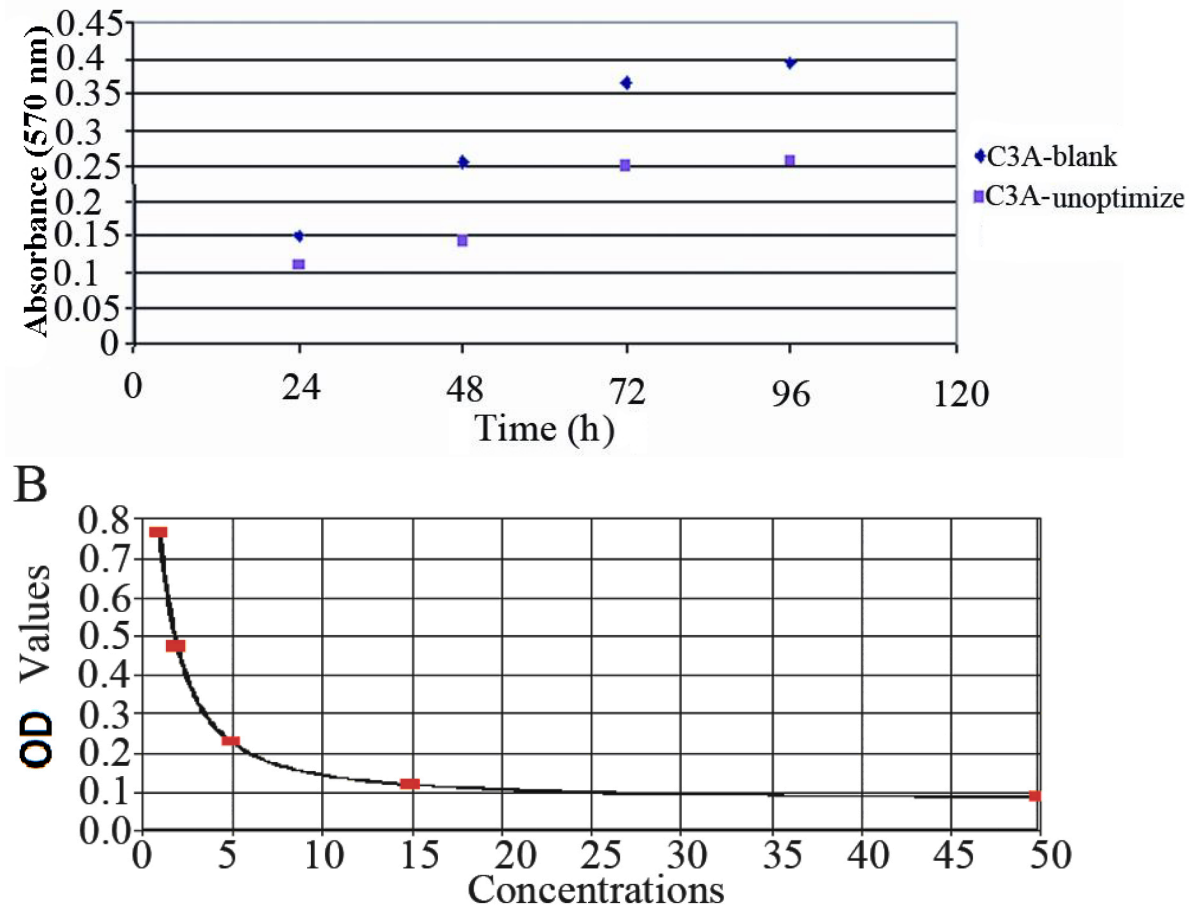

Figure 3. A. Cell growth in the blank and unoptimized C3A groups. B. Standard curves according to the standard concentration and optical density (OD) values.

\section{Synthetic function of hepatic cell lines}

The levels of prealbumin, cholinesterase, AFP, glucose, and creatinine were detected. The results showed no significant difference in prealbumin, cholinesterase, glucose, or creatinine between the two groups; however, the AFP content in the unoptimized C3A culture medium was significantly higher than that in the blank (Table 1).

The albumin content in the determined sample before and after transfection was determined according to the standard curves (Figure 3B), and no significant change was observed (Table 2). 
Table 1. Biochemical indicator results of blank C3A and unoptimized C3A culture supernatant.

\begin{tabular}{lcc}
\hline & Blank C3A & Unoptimized C3A \\
\hline Albumin $(\mathrm{g} / \mathrm{L})$ & $1.67 \pm 0.58$ & $1.33 \pm 0.58$ \\
Prealbumin $(\mathrm{mg} / \mathrm{L})$ & $3.33 \pm 0.58$ & 3 \\
Cholinesterase $(\mathrm{U} / \mathrm{L})$ & $20.67 \pm 18.77$ & $21.67 \pm 31.5$ \\
Alpha fetoprotein $(\mathrm{ng} / \mathrm{mL})$ & $114.33 \pm 2.08$ & $398.67 \pm 10.69^{* *}$ \\
Glucose $(\mathrm{mM})$ & $2.1 \pm 0.1$ & $1.52 \pm 0.39$ \\
\hline
\end{tabular}

Data are reported as means $\pm \mathrm{SD} . * * \mathrm{P}<0.01, * \mathrm{P}<0.05$.

Table 2. Albumin content of blank C3A and unoptimized C3A culture supernatant.
\begin{tabular}{lcc}
\hline & Blank C3A & Unoptimized C3A \\
\hline Albumin content $(\mu \mathrm{g} / \mathrm{mL})$ & $1.166 \pm 0.123$ & $1.119 \pm 0.086$ \\
\hline Data are reported as means \pm SD. &
\end{tabular}

\section{CYP 3A4 activity}

CYP 3A4 activity in the blank and unoptimized C3A groups was detected using chromatographic assays. The results showed hydroxylated MDZ formation in the blank but not in the unoptimized C3A group after $1 \mathrm{~h} \mathrm{MDZ}$ incubation (Figure 4). This finding indicates that CYP 3A4 in the unoptimized C3A cell lines was active, whereas the activity of that in the blank C3A was too low to detect.

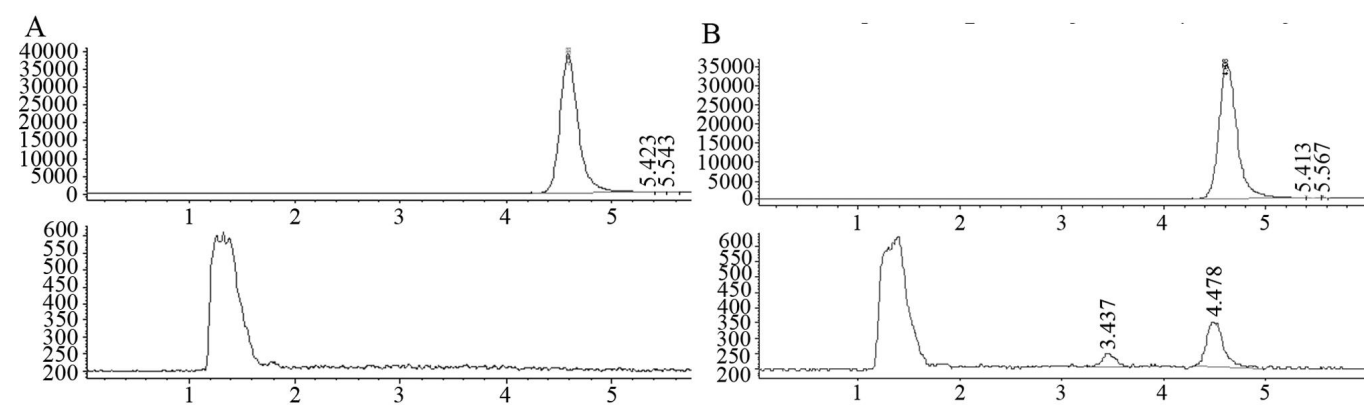

Figure 4. A. Chromatogram of the blank C3A cell lines after a 1-h MDZ $(1 \mu \mathrm{g} / \mathrm{mL})$ incubation. B. Chromatogram of the unoptimized C3A cell lines after a 1-h MDZ $(1 \mu \mathrm{g} / \mathrm{mL})$ incubation.

\section{Immunohistochemisty}

Immunohistochemisty results indicated GST A1 expression in the unoptimized C3A cell lines, whereas the GST A1 expression in the blank C3A lines was too low to detect (Figure 5).

\section{Lidocaine transformation assays}

Lidocaine transformation assays showed significant differences between the blank and unoptimized $\mathrm{C} 3 \mathrm{~A}$ cell lines in lidocaine metabolism at different detection times; the latter had a more powerful lidocaine metabolism ability with a $62.5 \%$ metabolic rate (Table 3 ). 


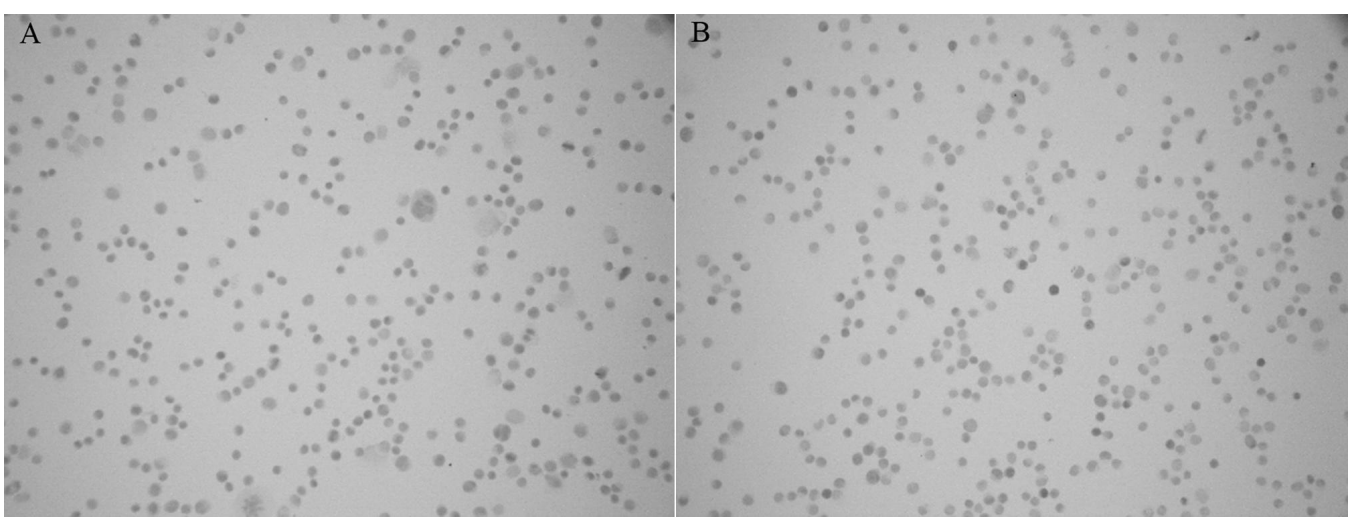

Figure 5. A. GST A1 expression in the blank C3A cell lines (200X). B. GST A1 expression in the unoptimized C3A cell lines (200X).

Table 3. Lidocaine transformation test results of blank C3A and unoptimized C3A cells.

\begin{tabular}{lcc}
\hline Time (h) & Blank C3A & Unoptimized C3A \\
\hline 0 & 80 & 80 \\
2 & $52.53 \pm 8.48$ & $39.99 \pm 10.83^{* *}$ \\
8 & $51.35 \pm 15.33$ & $35.11 \pm 5.49^{* *}$ \\
12 & $50.21 \pm 7.46$ & $35.08 \pm 2.25^{* *}$ \\
24 & $48.85 \pm 9.72$ & $30.66 \pm 4.14 * *$ \\
\hline
\end{tabular}

Data are reported as means $\pm \mathrm{SD}$ in $\mathrm{mg} / \mathrm{L} . * * \mathrm{P}<0.01$.

\section{DISCUSSION}

pBudCE4.1 is a double-expression vector with high expression in eukaryotic cells, and contains $\mathrm{CMV}$ and $\mathrm{EF}-1 \alpha$ promoters. In the present study, the unoptimized CYP $3 \mathrm{~A} 4$ and GST A1 fragments were obtained from the CYP 3A4 and GST A1 ORFs through PCR cloning. They were then cloned into pBudCE4.1. Gene sequencing confirmed that the construction of the recombinant plasmid pBudCE4.1-CYP 3A4-GST A1 was successful.

The most ideal cell material of the biochemical artificial liver reactor should possess all of the functions of human mature hepatocytes, such as biosynthesis, metabolism, and detoxification (Chamuleau et al., 2005; Hoque et al., 2007). Human hepatocytes are thought to be the most ideal cell material in an artificial liver because they are safe, have identical biological functions, and can provide homologous bioactive substances. However, their application is greatly restricted owing to lack of resources, high cost, difficult cell isolation procedures, and short lasting activity. C3A cell lines have been confirmed to be effective when used in an in vitro liver support system. As liver tumor cells, C3A cells can be obtained through isolation from human liver tumor tissues and cloning. They perform the basic functions of normal hepatocytes without a carcinogenic effect, and have therefore been widely used in clinical and experimental research of the in vitro liver support system (Shi et al., 1998; Liu et al., 2007).

To further improve the functions of C3A cells, enhance their drug metabolic ability, and relieve toxic injuries of endogenous metabolites to hepatocytes, the present study constructed CYP 3A4- and GST A1-expressing C3A cell lines. 
MTT assays showed that the unoptimized C3A cells transfected with pBudCE4.1CYP 3A4-GST A1 grew more slowly than the non-transfected blank C3A cells. This finding indicates that the increase in CYP 3A4 and/or GST A1 expression can bring about an inhibitory effect on cell growth. According to the literature, over-expressed GST T can inhibit the growth of cervical cancer HeLa cells and colonic cancer HCT116 cells, which is presumably due to the fact that GST T activates the associated factors of cell differentiation and proliferation regulating the G2-M phase transition. In addition, over-expressed GST T in HeLa and HCT116 cells increases the dependence of these cells on the growth factors and nutrient substances in serum, which can further restrict tumor cell growth as well as possibly reduce cellular malignancy (Qiao et al., 2008, 2009). GST A1 and GST T are members of the same family; hence, they might have the same cell growth inhibition mechanism.

This study found a significant increase in AFP in the cell culture medium of the unoptimized C3A cells. This finding indicates that an increase in CYP 3A4 and/or GST A1 might promote AFP expression. AFP is a tumor-related fetoprotein. It is often used as the serum marker of fetal defects and tumors to diagnose disease and to monitor disease progression. AFP can perform a lot of important physiological functions, including binding to and transferring numerous receptors (e.g., bilirubin, drugs), maintaining plasma colloid osmotic pressure (Gillespie and Uversky, 2000), performing bilateral regulatory functions as a growth regulatory factor (Li et al., 2002; Dudich et al., 2006; Oertel et al., 2006; Schnater et al., 2006), serving as a sensitive serum marker of primary liver cancer (Leerapun et al., 2007; Montaser et al., 2007), playing a role in the diagnosis of fetal defects or neonatal diseases (Dashe et al., 2006; Odibo et al., 2006; Rozenberg et al., 2006; Wald et al., 2006), and serving as a prognostic marker of acute hepatic failure (Amemiya et al., 2004; Butterfield, 2007). Therefore, AFP may play a positive role in the treatment of hepatic failure.

Furthermore, qPCR analysis showed that the CYP 3A4 and GST A1 expression levels were higher in the unoptimized C3A group than in the blank group (although cells in the former group did not grow as fast as those in the latter), and MDZ assays showed MDZ product formation in the unoptimized C3A cells and not in the blank C3A cells. These results indicate that CYP 3A4 in the unoptimized C3A cells was active. In addition, immunohistochemistry showed that GST A1 expression was positive in the unoptimized C3A cells but was negative in the blank $\mathrm{C} 3 \mathrm{~A}$. Lidocaine transformation assays showed that the transformation rate of the unoptimized C3A group was $62.5 \%$, which was significantly higher than that in the blank group (40\%).

Together, these results suggest that the drug metabolism function of unoptimized C3A could be improved after CYP 3A4 and GST A1 transfections, and that CYP 3A4- and GST A1-transfected C3A may become a cell material in the biochemical artificial liver system.

\section{ACKNOWLEDGMENTS}

Research supported by the 12th Five-Year National Science and Technology Major Project for Infectious Diseases (\#2012ZX10002004-005).

\section{REFERENCES}

Amemiya H, Kono K, Takahashi A, Kamei S, et al. (2004). c-Met expression in a gastric cancer cell line producing alphafetoprotein. Surg. Today 34: 115-122.

Bertz RJ and Granneman GR (1997). Use of in vitro and in vivo data to estimate the likelihood of metabolic pharmacokinetic interactions. Clin. Pharmacokinet. 32: 210-258. 
Butterfield LH (2007). Recent advances in immunotherapy for hepatocellular cancer. Swiss Med. Wkly. 137: 83-90.

Chalasani N, Gorski JC, Patel NH, Hall SD, et al. (2001). Hepatic and intestinal cytochrome P450 3A activity in cirrhosis: effects of transjugular intrahepatic portosystemic shunts. Hepatology 34: 1103-1108.

Chamuleau RA, Deurholt T and Hoekstra R (2005). Which are the right cells to be used in a bioartificial liver? Metab. Brain Dis. 20: 327-335.

Dashe JS, Twickler DM, Santos-Ramos R, McIntire DD, et al. (2006). Alpha-fetoprotein detection of neural tube defects and the impact of standard ultrasound. Am. J. Obstet. Gynecol. 195: 1623-1628.

Dudich E, Semenkova L, Dudich I, Denesyuk A, et al. (2006). Alpha-fetoprotein antagonizes X-linked inhibitor of apoptosis protein anticaspase activity and disrupts XIAP-caspase interaction. FEBS J. 273: 3837-3849.

Farrell G (1999). Effects of disease on expression and regulation of CYPs. Mol. Aspects Med. 20: 55-70, 137.

Gillespie JR and Uversky VN (2000). Structure and function of alpha-fetoprotein: a biophysical overview. Biochim. Biophys. Acta 1480: 41-56.

Hayes JD and Pulford DJ (1995). The glutathione S-transferase supergene family: regulation of GST and the contribution of the isoenzymes to cancer chemoprotection and drug resistance. Crit. Rev. Biochem. Mol. Biol. 30: 445-600.

Hoque ME, Mao HQ and Ramakrishna S (2007). Hybrid braided 3-D scaffold for bioartificial liver assist devices. $J$. Biomater. Sci. Polym. Ed. 18: 45-58.

Horiike N, Abe M, Kumagi T, Hiasa Y, et al. (2005). The quantification of cytochrome P-450 (CYP 3A4) mRNA in the blood of patients with viral liver diseases. Clin. Biochem. 38: 531-534.

Huet PM and Villeneuve JP (1983). Determinants of drug disposition in patients with cirrhosis. Hepatology 3: 913-918.

Johansson AS and Mannervik B (2001). Human glutathione transferase A3-3, a highly efficient catalyst of double-bond isomerization in the biosynthetic pathway of steroid hormones. J. Biol. Chem. 276: 33061-33065.

Kleinbloesem CH, van Harten J, Wilson JP, Danhof M, et al. (1986). Nifedipine: kinetics and hemodynamic effects in patients with liver cirrhosis after intravenous and oral administration. Clin. Pharmacol. Ther. 40: 21-28.

Leerapun A, Suravarapu SV, Bida JP, Clark RJ, et al. (2007). The utility of Lens culinaris agglutinin-reactive alphafetoprotein in the diagnosis of hepatocellular carcinoma: evaluation in a United States referral population. Clin. Gastroenterol. Hepatol. 5: 394-402.

Li MS, Li PF, Yang FY, He SP, et al. (2002). The intracellular mechanism of alpha-fetoprotein promoting the proliferation of NIH 3 T3 cells. Cell Res. 12: 151-156.

Liu HL, Xin SJ and Mao PY (2007). Selection of cell materials in bioartificial liver support system. J. Clin. Rehab. Tissue Engin. Res. 11: 9561-9565.

Lown K, Kolars J, Turgeon K, Merion R, et al. (1992). The erythromycin breath test selectively measures P450IIIA in patients with severe liver disease. Clin. Pharmacol. Ther. 51: 229-238.

McKinnon RA, Burgess WM, Hall PM, Roberts-Thomson SJ, et al. (1995). Characterisation of CYP3A gene subfamily expression in human gastrointestinal tissues. Gut 36: 259-267.

Montaser LM, Abbas OM, Saltah AM and Waked IA (2007). Circulating AFP mRNA as a possible indicator of hematogenous spread of HCC Cells: a possible association with HBV infection. J. Egypt. Natl. Canc. Inst. 19: 48-60.

Nelson DR, Koymans L, Kamataki T, Stegeman JJ, et al. (1996). P450 superfamily: update on new sequences, gene mapping, accession numbers and nomenclature. Pharmacogenetics 6: 1-42.

Odibo AO, Sehdev HM, Stamilio DM and Macones GA (2006). Evaluating the thresholds of abnormal second trimester multiple marker screening tests associated with intra-uterine growth restriction. Am. J. Perinatol. 23: 363-367.

Oertel M, Menthena A, Chen YQ and Shafritz DA (2006). Properties of cryopreserved fetal liver stem/progenitor cells that exhibit long-term repopulation of the normal rat liver. Stem Cells 24: 2244-2251.

Qiao HP, Jiao Y, Xu JY and Fan SJ (2008). Enhanced expression of GST $\theta$ inhibits growth and increases radiosensitivity in human uterine cervix cancer HeLa cells. Guide China Med. 6: 239-243.

Qiao HP, Jiao Y, Xu JY and Fan SJ (2009). Effects of GST0 on colon carcinoma cell line HCT116. Suzhou Univ. J. Med. Sci. 29: 7-10.

Rozenberg P, Bussieres L, Chevret S, Bernard JP, et al. (2006). Screening for Down syndrome using first-trimester combined screening followed by second-trimester ultrasound examination in an unselected population. Am. J. Obstet. Gynecol. 195: 1379-1387.

Schnater JM, Bruder E, Bertschin S, Woodtli T, et al. (2006). Subcutaneous and intrahepatic growth of human hepatoblastoma in immunodeficient mice. J. Hepatol. 45: 377-386.

Shi Q, Gaylor JD, Cousins R, Plevris J, et al. (1998). The effects of serum from patients with acute liver failure on the growth and metabolism of Hep G2 cells. Artif. Organs 22: 1023-1030.

Genetics and Molecular Research 13 (3): 6949-6961 (2014) 
Strange RC, Spiteri MA, Ramachandran S and Fryer AA (2001). Glutathione-S-transferase family of enzymes. Mutat. Res. 482: 21-26.

Wald NJ, Morris JK, Ibison J, Wu T, et al. (2006). Screening in early pregnancy for pre-eclampsia using Down syndrome quadruple test markers. Prenat. Diagn. 26: 559-564.

Yang LQ, Li SJ, Cao YF, Man XB, et al. (2003). Different alterations of cytochrome P450 3A4 isoform and its gene expression in livers of patients with chronic liver diseases. World J. Gastroenterol. 9: 359-363. 